\title{
An Analysis of Relationship between Stock Futures and Underlying Stock Volatility
}

\author{
Dr. Khurshid Ali Ganai \\ Assistant Professor, Business Division, \\ Higher Colleges of Technology, Sharjah Women's Campus, \\ United Arab Emirates.
}

\begin{abstract}
In this study, the researcher has undertaken an analysis to establish whether the introduction of stock futures trading influences the volatility of the underlying stock or not. In order to establish this, the researcher has taken eight companies into consideration which belongs to four different sectors such as pharmaceuticals, Banking, Oil and Gas and Fast Moving Consumer Goods sector. The researcher has taken a reference period of fourteen years which is sub-divided into two sub-groups namely pre-derivatives period, comprises of seven years from 1995-2001 and postderivatives period, comprises of seven years from 2002-2008. The findings put forth by the study confirms increased volatility during the post-derivatives period compared to pre-derivatives period. These findings collaborates with the findings of Lee and Oak (1992), Bechetti and Robert (1999) and Kamara et.al (1992).
\end{abstract}

Key Words: Stock futures, Underlying, Volatility, Derivatives.

\section{INTRODUCTION}

Volatility signifies the pace at which stock prices move higher and lower and if a stock is more volatile, it is implied that it is more risky as well. The level of volatility in the capital market has increased these days because of volatility in interest rates, commodity prices and exchange rates at national and international level. Therefore, the market participants are always concerned about the level of volatility of the market in which they are going to invest. This scenario motivates the regulators to look out for the new products that can facilitate the investing community in hedging the risk which is the outcome of volatility. Thus, the regulators always try to keep the level of volatility at reasonable levels so as to provide more controllable environment to the investors that in turn brings about a better level of confidence in the market-place which ultimately leads to higher levels of liquidity and lower levels of volatility. It is against this backdrop that the introduction of derivatives products were introduced in the Indian Capital Markets.

The concept of derivatives is, of course, not new to the Indian market. In the commodity markets they have a long history of over hundred years. In 1875, the first commodity futures exchange was set up in Mumbai under the guidance of Bombay Cotton Traders Association. The origin of these derivatives products can be traced long back when they were exhaustively used in the agriculture markets. The primary motivation for pre-arranging a buyer/seller for the stock or a commodity, in the early forwards contracts, was to lessen the possibility that large swing would inhibit marketing the commodity after the harvest. Therefore, these products initially emerged as hedging devices against fluctuations in commodity prices.

Financial derivatives, most notably forwards, futures and options came into spot-light in the post-1970s period by reason of growing instability in the financial markets which was the reflection of high volatility in exchange rates and interest rates. Through the use of derivatives, 
it has been possible to partially or fully transfer the risk by locking-in the asset prices. The first index futures contracts were traded at Kansas City Board of Trade. Currently, the most popular index futures contract in the world is based on S\&P 500 Index traded on Chicago Mercantile Exchange. During the mid-eighties, financial derivatives became the most active derivative instruments, generating volumes many more than the commodity futures. Since their emergence, these products have become so popular that by 1990s, they accounted for twothirds of the total transactions in derivatives products. In the recent years, the market for financial derivatives has grown tremendously in terms of the variety of instruments available, their complexity and also turnover. In the class of equity derivatives the world over, futures and options on stock indices have gained significant popularity than on individual stocks, especially among institutional investors, who are major players of index-linked derivatives, even small investors find these useful due to high correlation of the popular indices with various portfolio. Since their inception, the derivatives products have witnessed significant growth in terms of volumes. According to a study undertake by Sangmi, Khurshid and Khalid (2013) regarding the volume growth of derivatives products in the Indian Capital Market. The study established that the derivatives volumes have registered consistent growth throughout the reference period, however, the study also confirms some slowdown during the subprime crises.

\section{REVIEW OF LITERATURE}

The level of efficiency of a market determines its level of liquidity and volatility. In an efficient market, all information relevant for determining the value of a product is reflected in the current market price. A liquid market reflects truer price values and gives investors confidence in the market place. In this regard derivatives products represent some of the basic tools necessary in the mechanics of efficient capital markets. The economic functions of these derivatives contracts is to allow risks that formerly had been combined to be unbounded and transferred to those most willing to assume and manage each risk component. Thus, by virtue of derivatives application, risks are reduced and returns are increased.

The derivatives products also play a significant role in the price discovery that brings about effective dissemination of price information. In the absence of price information, investors, consumers and producers cannot make informed decisions. Thus, the wider the use of derivatives, the wider the dissemination of the price information. Therefore, one must underscore that futures exchanges are particularly adept at price discovery and dissemination of price information. This growing importance of derivatives in the present capital markets has made various researchers around the world to undertake the studies so as to determine its real impact on the various aspects of the capital market. The researcher has undertaken the review of some of the major studies undertaken by various researchers which is given below.

Lee Sang Bin and Ohk Ki Yod (1992) investigated in their study the relationship between stock index futures listing and structural changes in time-varying volatility. The sample of the study comprised five significant international index futures markets, such as, All Ordinaries Share Index (Sydney), Hang Seng (Hong Kong), NIKKEI (Tokyo), FTSE- 100 (London) and VLCI (New York). The findings they come up with, demonstrate that there is an increase in the spot market volatility following the introduction of NIKKEI, FTSE- 100 and VLCI Futures Contracts. But, in case of AOI and Hang Sang there is no evidence that can indicate that index futures induce volatility in the spot market, instead, Index Futures decrease the persistence of volatility shocks in the spot market. Ganai, K.A. (2019) undertook a study to investigate the dynamic relationship between Index Futures and Spot Index Volatility based on NIFTY-50 and the findings put forth by the study affirmed that the level of volatility has witnessed a 
downward trajectory in a significant manner throughout the post-derivatives period compared to pre-derivatives period.

M. Thenmozhi (2002) in her study on futures trading, information and spot price volatility of NIFTY-50 to investigate the impact of futures trading on the volatility of spot index returns. The main data for the study is the returns of the S\&P CNX NIFTY index futures and spot NIFTY index. The study, undertaken, reveals that there is a decline in volatility since the inception of futures trading which may be attributed to increase trading in cash market, due to faster dissemination of information, making cash market more liquid and less volatile. The study validates the statement by providing, statistically, significant difference between the volatility before and after the introduction of futures.

Bechetti, S. and Robert, D. J. (1999) in their study regarding index futures and spot market volatility come up with the findings that suggest that there exists a high correlation between Index futures and cash market volatility as the former (Index Futures) has had a significant impact on the latter (spot market) in controlling the level of volatility during the postderivatives period as compared to the pre-derivatives period during which the level of volatility in the spot market used to remain at higher levels.

Antonios Antonion and Phil Holmes (1995) undertake the study to examine the impact of trading in FTSE-100 stock index futures on the volatility of the underlying (spot market). They took daily closing prices of FTSE-100 Index, FTSE-500 Index and FT-30 Index for the period of November 1980 to October 1991, the results presented in the paper, suggest that there has been an impact of futures trading on the spot price volatility. In particular, the variance of price change pre-futures was integrated, suggesting shocks have a permanent effect on price change, whereas, post-futures sample is stationary which indicates that futures trading improves the quality and speed of information to spot markets as confirmed by the increase in the news coefficient.

Eric C. Chang at.al (1999) Undertook a study to examine Futures trading and stock market volatility and the results confirmed that for Nikkei stocks spot portfolio volatility increased and cross-sectional dispersion decreased compared with average volatility when Nikkei futures began trading on the Osaka Securities Exchange, but not on the Singapore International Monetary Exchange. For non-Nikkei stocks, no shift occurred when futures trading began on either exchange. Darren Butterworth (2010) investigated the effect of futures trading in the FTSE Mid 250 index on the underlying spot market using symmetric and asymmetric GARCH methods. The results of the study indicate that following the onset of futures trading the quantity of information flow into the market increased. However, the rate at which news is impounded into prices fell, with an associated rise in the persistence of information which in turn controlled volatility.

Kamara et.al (1992) investigate the effects of futures trading on the stability of the S\&P 500 returns. They witness the change in the volatility of the S\&P 500 index due to the introduction of futures trading for the period 1976 to 1987. The results show that the daily returns volatility is higher in the post futures period while the monthly returns remain unchanged. Mekenzie et.al (2001) in their study examine the impact of the introduction of stock index futures trading on the daily returns.The findings that the study comes up with suggested that the introduction of futures trading has been associated with reduced seasonality of mean return. Golaka, C. Nath (2006) study the behavior of volatility in cash market after the introduction of derivatives. The statistical scores in the study suggest that the volatility of the market as measured by 
benchmark indices like S\&P CNX NIFTY and S\&P CNX NIFTY JUNIOR have fallen in the postderivatives period.

The present study has been undertaken with the following Objectives:

1) To study the behaviour of volatility of the underlying stocks during pre-derivatives and post-derivatives period.

2) To assess the impact of stock futures trading on the underlying stock volatility.

3) To draw conclusion regarding the impact of stock futures trading on the volatility of the underlying stock.

\section{Hypothesis:}

H0: The onset of stock futures trading does not cause any change in the volatility of the underlying stocks.

H1: The onset of stock futures trading causes a change in the volatility of the underlying stocks.

\section{DATA-BASE AND METHODOLOGY}

So as to accomplish the objectives of the study, the researcher has collected the relevant intraday data from the National Stock Exchange. The data collected is then divided into two sub-groups, namely, pre-derivatives period and post derivatives period. The daily observations are recorded and then the mean of every day's observation is calculated by taking into consideration the previous close price, open price, high price, low price, last price and close price. The mean of every trading day stands as the representative of that day and is taken as a base to calculate the quarter mean, standard deviation and variance.

In the present study two reference periods are taken into consideration so as to achieve the set objectives of the study and are divided into two sub-groups. The first sub-group that stands as the pre-derivatives period has been taken from ( $1^{\text {st }}$ January $1995-30^{\text {th }}$ September 2001). It is the period during which stock futures were yet to be introduced by the National Stock Exchange on individual stocks. The researcher has left out the fourth quarter of 2001 (1 $1^{\text {st }}$ oct.$31^{\text {st }}$ Dec.) so as to exclude the reaction period of the spot market towards the introduction of stock futures. The second sub-group that stands as the post-derivatives period has been taken from (1st January 2002 to $31^{\text {st }}$ December 2008). It is the period during which stock futures were available on the sample stocks at the National Stock Exchange. 
ANALYSIS AND INTERPRETATION
Table-1
ANALYSIS OF VOLATILITY OF CIPLA DURING PRE-DERIVATIVES AND POST-DERIVATIVES PERIOD

\begin{tabular}{|cccccccccc|}
\hline & \multicolumn{4}{c}{ PRE-DERIVATIVES } & \multicolumn{3}{c}{ Year } & \multicolumn{3}{c|}{ POST-DERIVATIVES } \\
\hline & Near & MEAN & $\begin{array}{c}\text { STD. } \\
\text { DEV }\end{array}$ & VAR & & N & MEAN & $\begin{array}{c}\text { STD. } \\
\text { DEV }\end{array}$ & VAR \\
\hline 1995 & 246 & 452.94 & 121.63 & 14795.68 & 2002 & 251 & 982.53 & 82.18 & 6753.55 \\
\hline 1996 & 250 & 399.95 & 43.79 & 1918.38 & 2003 & 254 & 897.42 & 189.64 & 35963.45 \\
\hline 1997 & 244 & 657.81 & 85.10 & 7242.19 & 2004 & 254 & 604.47 & 474.38 & 225038.40 \\
\hline 1998 & 250 & 770.84 & 111.27 & 12382.48 & 2005 & 251 & 322.74 & 55.28 & 3056.26 \\
\hline 1999 & 254 & 1784.24 & 263.77 & 69577.03 & 2006 & 250 & 334.57 & 149.51 & 22355.73 \\
\hline 2000 & 250 & 938.92 & 185.78 & 34516.73 & 2007 & 249 & 209.02 & 26.16 & 684.81 \\
\hline 2001 & 188 & 1097.47 & 73.36 & 5382.77 & 2008 & 246 & 207.23 & 17.67 & 312.50 \\
\hline
\end{tabular}

Source: - Compiled from the data taken from NSE India

In the table 1.1 the first year of the pre-derivatives period records the level of volatility at 121.63 mark in terms of standard deviation. This is followed by a substantial decline in the subsequent year by $63.99 \%$ which pushes down the level of volatility to 43.79 mark that also stands as the lowest level of volatility throughout the pre-derivatives period. The third year records an increase in the level of volatility by $94.33 \%$, touching 85.10 mark. This upward trajectory continues in the subsequent year that registers an increase of $30.75 \%$, touching 111.27 mark in terms of standard deviation. The fifth year records a further increase in the level of volatility by $137.05 \%$ which further pushes up the level of volatility to 263.77 mark that also stands as the highest level of volatility in terms of standard deviation throughout the pre-derivatives period. However, the subsequent year witnesses a decline in the level of volatility by $29.56 \%$ that pushes down the volatility level to 185.78 mark. This downward trend continues in the last year as well by 60.51\%, touching 73.36 mark. The spread of volatility in terms of standard deviation throughout the pre-derivatives period stands at (43.79-263.77) levels, besides, the average level of volatility stands at 126.36 levels throughout the pre-derivatives period.

The post-derivatives period in the first year records the level of volatility at 82.18 mark in terms of standard deviation. This is followed by a significant increase in the level of volatility by $130.76 \%$ that takes the volatility level to 189.64 mark. This upward trajectory continues in the subsequent year as well that witnesses an increase of $13.52 \%$ in the level of volatility, touching 474.38 mark that also stands as the highest level of volatility throughout the postderivatives period. This upward trend in the level of volatility comes to an end in the fourth year of the pre-derivatives period that registers a decline of $74.32 \%$ that pushes down the level of volatility to 55.28 mark. But, the subsequent year again records an increase in the level of volatility by $170.45 \%$, touching 149.51 mark. However, the sixth year records a substantial decline as the level of volatility touches 26.16 mark. This downward trend in the level of volatility continues in the last year of pre-derivatives period which registers volatility at 17.67 mark that also stands as the lowest level of volatility in terms of standard deviation throughout the post-derivatives period. The spread of volatility in terms of standard deviation throughout 
the post-derivatives period stands at (17.67-474.38) levels, besides, the average level of volatility throughout the post-derivatives period stands at 142.11Levels.

Table-II

ANALYSIS OF VOLATILITY OF RANBAXY DURING PRE-DERIVATIVES AND POST-DERIVATIVES PERIOD

\begin{tabular}{|c|c|c|c|c|c|c|c|c|c|}
\hline \multirow{2}{*}{ Year } & \multicolumn{4}{|c|}{ PRE-DERIVATIVES } & \multirow{2}{*}{ Year } & \multicolumn{4}{|c|}{ POST-DERIVATIVES } \\
\hline & $\mathrm{N}$ & MEAN & $\begin{array}{l}\text { STD. } \\
\text { DEV }\end{array}$ & VAR & & $\mathrm{N}$ & MEAN & $\begin{array}{l}\text { STD. } \\
\text { DEV }\end{array}$ & VAR \\
\hline 1995 & 246 & 644.60 & 48.11 & 2315.29 & 2002 & 251 & 772.69 & 141.31 & 19969.13 \\
\hline 1996 & 250 & 629.77 & 41.46 & 1719.16 & 2003 & 254 & 809.33 & 171.91 & 29555.18 \\
\hline 1997 & 244 & 651.73 & 45.97 & 2113.73 & 2004 & 254 & 1029.74 & 86.60 & 7500.59 \\
\hline 1998 & 250 & 568.61 & 137.79 & 18987.96 & 2005 & 251 & 783.05 & 300.92 & 90557.93 \\
\hline 1999 & 254 & 751.50 & 263.77 & 69577.03 & 2006 & 250 & 407.70 & 38.37 & 1472.67 \\
\hline 2000 & 250 & 703.14 & 136.00 & 18498.42 & 2007 & 249 & 386.47 & 32.75 & 1073.12 \\
\hline 2001 & 188 & 566.80 & 78.96 & 6235.90 & 2008 & 246 & 402.24 & 111.87 & 12515.13 \\
\hline
\end{tabular}

Source: - Compiled from the data taken from NSE India

In the table 1.3 the pre-derivatives period records the level of volatility at 48.11 mark in terms of standard deviation which is followed by a decline by $13.82 \%$, pushing down the level of volatility to 41.46 mark that also stands as the lowest level of volatility throughout the prederivatives period. However, the third year records an increase of $10.87 \%$ that pushes up the level of volatility to 45.49 mark. This upward trajectory in the level of volatility continues in the subsequent year as well that records an increase of $199.79 \%$, touching 137.79 mark of volatility in terms of standard deviation. In the fifth year a further increase in the level of volatility is witnessed, that takes up the level of volatility to 263.77 mark that also stands as the highest level of volatility in terms of standard deviation throughout the pre-derivatives period. This upward trend in the level of volatility comes to an end in the sixth year that records a significant decline of $91.42 \%$, touching 136.00 mark. This decline in the level of volatility continues in the last year as well that records the level of volatility at 78.96 mark. The spread of volatility in terms of standard deviation throughout the pre-derivatives period stands at (41.46-263.77) levels, besides, the average level of volatility throughout the pre-derivatives period stands at 107.43 levels.

The post-derivatives period records the level of volatility at 141.31 mark in terms of standard deviation which is followed by a significant increase in the level of volatility by $21.65 \%$ that takes the level of volatility to 171.91 mark. However, the third year witnesses a decline in the level of volatility by $49.62 \%$, touching 86.60 mark. But, the subsequent year again records jump volatility by $247.48 \%$, pushing the level of volatility to 300.92 mark in terms of standard deviation that also stands as the highest level of volatility throughout the post-derivatives period. However, the fifth year of the post-derivatives period records a decline of $87.24 \%$, pushing down the level of volatility to 38.37 mark. This downward trajectory in the level of volatility continues in the subsequent year as well that witnesses a decline of $15.03 \%$, touching 32.75 mark that also stands as the lowest level of volatility in terms of standard deviation throughout the post-derivatives period. The last year records an increase in the level of volatility by $241.58 \%$ that pushes up the level of volatility to 111.87 mark. The spread of 
volatility in terms of standard deviation throughout the post-derivatives period stands at (32.75-300.92) levels, besides, the average level of volatility throughout the post-derivatives period stands at 126.24 levels.

Table-III

ANALYSIS OF VOLTALITY OF ICICI DURING PRE-DERIVATIVE AND POST-DERIVATIVES PERIOD

\begin{tabular}{|c|c|c|c|c|c|c|c|c|c|}
\hline \multirow[b]{2}{*}{ Year } & \multicolumn{4}{|c|}{ PRE-DERIVATIVES } & \multirow[t]{2}{*}{ Year } & \multicolumn{4}{|c|}{ POST-DERIVATIVES } \\
\hline & $\mathbf{N}$ & MEAN & $\begin{array}{l}\text { STD. } \\
\text { DEV }\end{array}$ & VAR & & $\mathbf{N}$ & MEAN & $\begin{array}{l}\text { STD. } \\
\text { DEV }\end{array}$ & VAR \\
\hline 1995 & 246 & 274.39 & 192.89 & 37207.21 & 2002 & 251 & 104.71 & 16.90 & 1675.26 \\
\hline 1996 & 250 & 81.32 & 17.07 & 291.49 & 2003 & 254 & 174.71 & 47.69 & 2274.51 \\
\hline 1997 & 244 & 77.06 & 14.02 & 196.65 & 2004 & 254 & 291.22 & 31.81 & 1012.43 \\
\hline 1998 & 250 & 74.57 & 20.77 & 431.70 & 2005 & 251 & 452.64 & 73.97 & 5471.81 \\
\hline 1999 & 254 & 69.54 & 18.71 & 350.34 & 2006 & 250 & 635.74 & 115.08 & 13245.29 \\
\hline 2000 & 250 & 118.61 & 25.69 & 660.06 & 2007 & 249 & 976.94 & 124.07 & 15395.80 \\
\hline 2001 & 188 & 78.06 & 17.19 & 295.77 & 2008 & 246 & 745.14 & 276.28 & 76333.07 \\
\hline
\end{tabular}

Source: - Compiled from the data taken from NSE India

In the table 1.6 the behaviour of volatility is highly consistent as the level of volatility remains at lower levels throughout the pre-derivatives period. In the first year the pre-derivatives period records the level of volatility at 398.52 mark in terms of standard deviation that also stands as the highest level of volatility throughout the pre-derivatives period which is followed by a significant decline by $91.15 \%$ that pushes down the level of volatility to 17.07 mark. This downward trajectory in the level of volatility continues in the third year as well that records the level of volatility at 14.02 mark, decreasing by $17.86 \%$ that also stands as the lowest level of volatility in terms of standard deviation throughout the pre-derivatives period. However, the third year registers an increase by $48.14 \%$, touching 20.77 mark. But the subsequent year witnesses a marginal decline by $9.91 \%$ that pushes down the volatility level to 18.71 mark in terms of standard deviation. In the sixth year the level of volatility again witnesses an increase of $37.30 \%$, pushing up the level of volatility to 25.69 mark, followed by a decline of $33.08 \%$ that takes the level of volatility to 17.19 mark. The spread of volatility in terms of standard deviation throughout the pre-derivatives period stands at (14.02-192.89) levels, besides, the average level of volatility throughout the pre-derivatives period stands at 43.76 levels.

The post-derivatives period records the level of volatility at 16.90 mark in the first year in terms of standard deviation that also stands as the lowest level of volatility throughout the post-derivatives period which is followed by a substantial increase by $182.18 \%$ that takes the level of volatility to 47.69 mark. But the third year witnesses a decline in the level of volatility by $33.29 \%$, touching 31.81 mark. In the fourth year the level of volatility registers a substantial increase by $132.53 \%$ that pushes up the level of volatility to 73.97 mark which is followed by a further increase in the level of volatility by 55.57\%, touching 115.08 mark. This upward trajectory in the level of volatility continues in the sixth year as well that takes the level of volatility to 124.07 mark in terms of standard deviation. The last year records a further increase in the level of volatility by $122.68 \%$, pushing up the level of volatility to 276.28 mark that also stands as the highest level of volatility in terms of standard deviation throughout the post-derivatives period. The spread of volatility in terms of standard deviation throughout the 
post-derivatives period stands at (16.90-398.52) levels, besides, the average level of volatility throughout the post-derivatives period stands at 91.97 levels.

Table-IV

ANALYSIS OF VOLATILITYY OF STATE BANK OF INDIA DURING PRE-DERIVATIVES AND POSTDERIVATIVES PERIOD

\begin{tabular}{|c|c|c|c|c|c|c|c|c|c|}
\hline \multirow[b]{2}{*}{ Year } & \multicolumn{4}{|c|}{ PRE-DERIVATIVES } & \multirow[b]{2}{*}{ Year } & \multicolumn{4}{|c|}{ POST-DERIVATIVES } \\
\hline & $\mathrm{N}$ & MEAN & $\begin{array}{l}\text { STD. } \\
\text { DEV }\end{array}$ & VAR & & $\mathrm{N}$ & MEAN & $\begin{array}{l}\text { STD. } \\
\text { DEV }\end{array}$ & VAR \\
\hline 1995 & 246 & 191.96 & 16.29 & 265.41 & 2002 & 251 & 235.44 & 17.02 & 289.68 \\
\hline 1996 & 250 & 253.80 & 37.42 & 1400.81 & 2003 & 254 & 379.27 & 80.33 & 6453.15 \\
\hline 1997 & 244 & 289.26 & 35.79 & 1281.05 & 2004 & 254 & 530.06 & 78.03 & 6089.66 \\
\hline 1998 & 250 & 216.08 & 45.59 & 2079.10 & 2005 & 251 & 751.17 & 113.60 & 12905.39 \\
\hline 1999 & 254 & 219.22 & 36.76 & 1351.72 & 2006 & 250 & 951.31 & 154.21 & 23781.25 \\
\hline 2000 & 250 & 205.30 & 26.68 & 712.33 & 2007 & 249 & 1535.51 & 442.03 & 195391.80 \\
\hline 2001 & 188 & 216.22 & 22.16 & 491.40 & 2008 & 246 & 1581.60 & 379.57 & 144074.70 \\
\hline
\end{tabular}

Source: - Compiled from the data taken from NSE India

In the table 1.8 the pre-derivatives period records the level of volatility at 16.29 mark in terms of standard deviation in the first year that also stands as the lowest level of volatility throughout the pre-derivatives period. This is followed by a substantial increase in the level of volatility in the subsequent year by $129.71 \%$, touching 37.42 mark. But, the third year records a marginal decline in the level of volatility by $4.35 \%$, touching 35.79 mark, followed by a significant increase in the fourth year by $27.38 \%$ that takes the level of volatility to 45.59 mark that also stands as the highest level of volatility in terms of standard deviation throughout the pre-derivatives period. However, the subsequent year witnesses a decline in the level of volatility by $19.36 \%$, touching 36.76 mark. This downward trajectory in the level of volatility continues in the sixth year as well, as the volatility level touches 26.68 mark, followed by a further decline in the last year by $16.94 \%$, touching 22.16 mark. The spread of volatility throughout the pre-derivatives period stands at (16.29-45.59) levels, besides, the average level of volatility stands at 31.52 mark in terms of standard deviation throughout the prederivatives period.

The post-derivatives period records the level of volatility at 11.02 mark in the first year in terms of standard deviation that also stands as the lowest level of volatility throughout the post-derivatives period. This is followed by a substantial increase in the subsequent year as the level of volatility touches 80.33 mark, recording an increase of $371.97 \%$.However, the third year of the post-derivatives period registers a marginal decline in the level of volatility by $2.86 \%$, touching 78.03 mark. But, this is followed by a substantial increase in the level of volatility by $45.58 \%$ in the subsequent year that pushes up the level of volatility to 113.60 mark. The fifth year registers a further rise in the level of volatility by $35.74 \%$, pushing the level of volatility to 154.21 mark. This upward trajectory in the level of volatility continues in the fifth year as well that takes volatility level to 442.03 mark which also stands as the highest level of volatility in terms of standard deviation throughout the post-derivatives period. The last year witnesses a decline in the level of volatility by $14.13 \%$, touching 379.57 mark. The 
spread of volatility throughout the post-derivatives period stands at (11.02-442.03) levels, besides, the average level of volatility stands at 180.68 mark in terms of standard deviation throughout the post-derivatives period

\begin{tabular}{|c|c|c|c|c|c|c|c|c|c|}
\hline \multirow[b]{2}{*}{ Year } & \multicolumn{4}{|c|}{ PRE-DERIVATIVES } & \multirow[b]{2}{*}{ Year } & \multicolumn{4}{|c|}{ POST-DERIVATIVES } \\
\hline & $\mathrm{N}$ & MEAN & $\begin{array}{l}\text { STD. } \\
\text { DEV }\end{array}$ & VAR & & $\mathrm{N}$ & MEAN & $\begin{array}{l}\text { STD. } \\
\text { DEV }\end{array}$ & VAR \\
\hline 1995 & 246 & 326.04 & 20.64 & 426.25 & 2002 & 251 & 249.45 & 46.27 & 2141.33 \\
\hline 1996 & 250 & 340.79 & 32.09 & 1030.15 & 2003 & 254 & 334.58 & 40.54 & 1643.69 \\
\hline 1997 & 244 & 438.73 & 47.90 & 2294.51 & 2004 & 254 & 380.54 & 73.18 & 5447.95 \\
\hline 1998 & 250 & 350.91 & 78.65 & 6187.35 & 2005 & 251 & 324.02 & 21.85 & 477.71 \\
\hline 1999 & 254 & 220.24 & 37.18 & 1382.74 & 2006 & 250 & 293.82 & 37.32 & 1392.93 \\
\hline 2000 & 250 & 132.41 & 21.52 & 463.17 & 2007 & 249 & 270.75 & 26.13 & 682.83 \\
\hline 2001 & 188 & 157.99 & 21.64 & 470.67 & 2008 & 246 & 244.21 & 40.88 & 1671.71 \\
\hline
\end{tabular}

Source: - Compiled from the data taken from NSE India

In the table 1.14 the first year of the pre-derivatives period records the level of volatility at 20.64 mark in terms of standard deviation that also stands as the lowest level of volatility throughout the pre-derivatives period. This is followed by a substantial increase in the subsequent year by $55.47 \%$ that pushes up the level of volatility to 32.09 mark. This upward trajectory in the level of volatility continues in the third year of the pre-derivatives period as well in which the level of volatility touches 47.90 mark, increasing by $49.26 \%$. The fourth year of the pre-derivatives period witnesses a further rise in the level of volatility by $64.19 \%$, touching 78.65 mark that also stands as the highest level of volatility throughout the prederivatives period. This upward trajectory comes to an end in the subsequent year that witnesses a decline of $52.72 \%$, touching 37.18 mark in terms of standard deviation. This downward movement in the level of volatility continues in the subsequent year as well that pushes the volatility level to 21.52 mark, declining by $42.11 \%$.The last year of the prederivatives period records a marginal increase in the level of volatility by $0.55 \%$, touching 21.69 mark. The spread of volatility throughout the pre-derivatives period stands at (20.6478.65) levels, besides, the average level of volatility stands at 37.08 mark in terms of standard deviation throughout the pre-derivatives period.

The post-derivatives period in the first year records the level of volatility at 46.27 mark in terms of standard deviation. This is followed by a decline in the level of volatility by $12.38 \%$, touching 40.54 mark. The third year of post-derivatives period witnesses a substantial increase in the level of volatility by $80.51 \%$ that pushes up the level of volatility to 73.81 mark in terms of standard deviation which also stands as the highest level of volatility throughout the postderivatives period. But, the subsequent year witnesses a substantial fall in the level of volatility by $70.14 \%$ that pushes down the volatility level, to 21.85 mark in terms of standard deviation that also stands as the lowest level of volatility throughout the post-derivatives period. The fifth year again takes an upward movement in the level of volatility by $70.80 \%$, touching 37.32 mark. This is followed by a decline in the subsequent year as the level of volatility comes down 
to 26.13 mark. The last year of the post-derivatives period registers an increase in the level of volatility by $56.44 \%$, touching 40.88 mark. The spread of volatility throughout the postderivatives period stands at (21.85-73.81) levels, besides, the average level of volatility stands at 40.88 mark in terms of standard deviation throughout the post-derivatives period.

TABLE-VI

ANALYSIS OF VOLATILITY OF RELIANCE INDUSTRIES LIMITED DURING PRE-DERIVATIVES AND POST-DERIVATIVES PERIOD

\begin{tabular}{|cccccccccc|}
\hline \multicolumn{1}{c}{ Year } & \multicolumn{3}{c}{ PRE-DERIVATIVES } & & \multicolumn{4}{c|}{ POST-DERIVATIVES } \\
\hline 1995 & N & MEAN & $\begin{array}{c}\text { STD. } \\
\text { DEV }\end{array}$ & VAR & Year & N & MEAN & $\begin{array}{c}\text { STD. } \\
\text { DEV }\end{array}$ & VAR \\
\hline 1996 & 246 & 260.80 & 23.57 & 555.76 & 2002 & 251 & 279.65 & 25.99 & 675.53 \\
\hline 1997 & 244 & 299.73 & 22.50 & 506.32 & 2003 & 254 & 360.85 & 84.87 & 7203.13 \\
\hline 1998 & 250 & 144.60 & 27.74 & 770.00 & 2005 & 251 & 657.08 & 118.05 & 13936.33 \\
\hline 1999 & 254 & 178.15 & 40.59 & 1648.13 & 2006 & 250 & 1010.13 & 186.52 & 34791.87 \\
\hline 2000 & 250 & 326.16 & 30.19 & 911.71 & 2007 & 249 & 1907.14 & 358.55 & 128653.30 \\
\hline 2001 & 188 & 352.49 & 43.65 & 1906.01 & 2008 & 246 & 2108.35 & 313.16 & 98161.13 \\
\hline
\end{tabular}

Source: - Compiled from the data taken from NSE India

In the table 1.15 the first year of the pre-derivatives period records the level of volatility at 23.57 mark in terms of standard deviation which is followed by a marginal decline in the subsequent year by $4.53 \%$, touching 22.50 mark in terms of standard deviation that also stands as the lowest level of volatility throughout the pre-derivatives period. However, the third year witnesses a substantial increase in the level of volatility by $219.06 \%$, touching 71.79 mark in terms of standard deviation that also stands as the highest level of volatility throughout the pre-derivatives period. But in the fourth year a significant decline is registered that pushes down the level of volatility to 27.74 mark, decreasing by $61.35 \%$.This declining trend could not sustain as the subsequent year witnesses an increase of $46.32 \%$ that pushes up the level of volatility to 40.59 mark. The sixth year again registers a decline of $25.62 \%$, touching 30.19 mark, followed by an increase in the last year by $44.58 \%$ that takes the level of volatility to 43.65 mark. The spread of volatility throughout the pre-derivatives period stands at (22.50-71.79) levels, besides, the average level of volatility stands at 37.14 mark in terms of standard deviation throughout the pre-derivatives period.

The post-derivatives period records the level of volatility at 25.99 mark in the first year in terms of standard deviation that also stands as the lowest level of volatility throughout the post-derivatives period. This is followed by a substantial increase by $226.54 \%$ that pushes up the level of volatility to 84.87 mark. But the subsequent year witnesses a decline in the level of volatility by $40.36 \%$, touching 50.61 mark in terms of standard deviation. The fourth year of the post-derivatives period records an increase of $133.25 \%$ in the level of volatility that takes it to 118.05 mark. This upward trajectory continues in the subsequent year as well that witnesses an increase of $58.00 \%$, thus, pushing up the level of volatility to 186.52 mark. The sixth year further records an increase in the level of volatility by $92.23 \%$, touching 358.55 mark that also stands as the highest level of volatility in terms of standard deviation 
throughout the post-derivatives period. The last year of the post-derivatives period records a marginal decline in the level of volatility by $12.65 \%$ that takes the level of volatility to 313.16 mark. The spread of volatility throughout the post-derivatives period in terms of standard deviation stands at (25.99-535.43) levels, besides, the average level of volatility stands at 162.53 mark in terms of standard deviation throughout the post-derivatives period.

\section{Table-VII \\ ANALYSIS OF VOLATILITY OF HINDUSTAN UNILEVER LIMITED DURING PRE-DERIVATIVES AND POST-DERIVATIVES PERIOD}

\begin{tabular}{|ccccccccccc|}
\hline \multicolumn{1}{c}{} & \multicolumn{3}{c}{ PRE-DERIVATIVES } \\
Year & N & MEAN & $\begin{array}{c}\text { STD. } \\
\text { DEV }\end{array}$ & VAR & Year & & POST-DERIVATIVES \\
\hline 1995 & 246 & 590.42 & 22.05 & 486.37 & 2002 & 251 & 196.40 & 24.70 & 610.38 \\
\hline 1996 & 250 & 776.76 & 71.58 & 5124.15 & 2003 & 254 & 171.73 & 16.13 & 260.23 \\
\hline 1997 & 244 & 1200.80 & 207.11 & 42894.70 & 2004 & 254 & 143.42 & 26.79 & 717.94 \\
\hline 1998 & 250 & 1584.56 & 98.61 & 9724.86 & 2005 & 251 & 157.72 & 18.58 & 345.30 \\
\hline 1999 & 254 & 2295.75 & 261.41 & 68337.23 & 2006 & 250 & 237.07 & 24.09 & 610.17 \\
\hline 2000 & 250 & 1387.73 & 300.19 & 90447.23 & 2007 & 249 & 208.58 & 11.52 & 132.91 \\
\hline 2001 & 188 & 209.58 & 10.03 & 100.61 & 2008 & 246 & 232.59 & 15.78 & 249.20 \\
\hline \hline
\end{tabular}

Source: - Compiled from the data taken from NSE India

In the table 1.16 the pre-derivatives period records the level of volatility in the first year at 22.05 mark in terms of standard deviation, followed by a substantial increase in the subsequent year in which the level of volatility touches 71.58 mark, recording an increase of $224.62 \%$. This increase in the level of volatility continues in the third year as well that pushes up the level of volatility to 207.11 mark, increasing by $189.34 \%$. However, the fourth year registers a decline in the level of volatility by $52.38 \%$ that takes the level of volatility to 98.61 mark. But, this decline in the level of volatility could not sustain as the subsequent year records a substantial increase in the level of volatility by $165.09 \%$, touching 261.41 mark. This upward trajectory in the level of volatility continues in the sixth year as well in which the level of volatility touches 300.19 mark, increasing by $14.83 \%$ that also stands as the highest level of volatility throughout the pre-derivatives period. The last year records a significant decline by $96.65 \%$ that pushes down the volatility level to 10.03 mark that also stands as the lowest level of volatility in terms of standard deviation throughout the pre-derivative period. The spread of volatility throughout the pre-derivatives period stands at (10.03-1174.03) levels, besides, the average level of volatility stands at 138.71 mark in terms of standard deviation throughout the pre-derivatives period.

The figures of the post-derivatives period depict that the level of volatility throughout the postderivatives period remains consistently within the reasonable levels as the level of volatility in the first year is recorded at 24.70 mark in terms of standard deviation which is followed by a further decline by $34.69 \%$ that pushes down the level of volatility to 16.13 mark. The third year of the post-derivatives period records an increase in the level of volatility by $66.08 \%$, touching 26.79 mark that also stands as the highest level of volatility in terms of standard 
deviation throughout the post-derivatives period. However, the subsequent year records a decline in the level of volatility by $30.64 \%$ that pushes down the level of volatility to 18.58 mark. But, the fifth year again takes an upward movement that takes the level of volatility to 24.69 mark. However, the subsequent year witnesses a decline in the level of volatility by $52.17 \%$, touching 11.52 mark that also stands as the lowest level of volatility in terms of standard deviation throughout the post-derivatives period. The last year witnesses an increase as the level of volatility touches 15.78 mark , increasing by $36.97 \%$. The spread of volatility throughout the post-derivatives period stands at (11.52-26.79) levels, besides, the average level of volatility stands at 19.65 mark in terms of standard deviation throughout the postderivatives period.

Table-VIII

ANALYSIS OF VOLATILITY OF INDIAN TOBACCO COMPANY DURING PRE-DERIVATIVES AND POST-DERIVATIVES PERIOD

\begin{tabular}{|c|c|c|c|c|c|c|c|c|c|}
\hline \multicolumn{6}{|c|}{ PRE-DERIVATIVES } & \multicolumn{4}{|c|}{ POST-DERIVATIVES } \\
\hline Year & $\mathrm{N}$ & MEAN & $\begin{array}{l}\text { STD. } \\
\text { DEV }\end{array}$ & VAR & Year & $\mathrm{N}$ & MEAN & $\begin{array}{l}\text { STD. } \\
\text { DEV }\end{array}$ & VAR \\
\hline 1995 & 246 & 261.90 & 33.57 & 1127.12 & 2002 & 251 & 666.93 & 40.34 & 1628.00 \\
\hline 1996 & 250 & 277.40 & 30.12 & 907.50 & 2003 & 254 & 755.26 & 103.49 & 10710.95 \\
\hline 1997 & 244 & 490.62 & 81.72 & 6674.29 & 2004 & 254 & 1069.95 & 110.19 & 12142.69 \\
\hline 1998 & 250 & 679.38 & 62.94 & 3961.75 & 2005 & 251 & 1122.87 & 207.25 & 43259.15 \\
\hline 1999 & 254 & 906.10 & 132.14 & 17463.21 & 2006 & 250 & 177.83 & 15.46 & 239.30 \\
\hline 2000 & 250 & 763.24 & 93.89 & 8816.31 & 2007 & 249 & 169.78 & 14.60 & 213.16 \\
\hline 2001 & 188 & 786.98 & 71.70 & 5141.66 & 2008 & 246 & 212.12 & 18.44 & 340.20 \\
\hline
\end{tabular}

Source: - Compiled from the data taken from NSE India

In the table 1.17 the first year of the pre-derivatives period records the level of volatility at 33.57 mark in terms of standard deviation which is followed by a decline by $10.27 \%$ that pushes down the level of volatility to 30.12 mark which also stands as the lowest level of volatility in terms of standard deviation throughout the pre-derivatives period. The third year witnesses a substantial increase in the level of volatility by $171.31 \%$ that pushes up the volatility level to 81.72 mark in terms of standard deviation. However, the subsequent year registers a substantial decline in the level of volatility by $22.98 \%$, touching 62.44 mark. But the fifth year of the pre-derivatives period records a significant increase in the level of volatility by $109.94 \%$ that pushes up the level of volatility to 132.14 mark in terms of standard deviation that also stands as the highest level of volatility throughout the pre-derivatives period. This is followed by a decline by $28.94 \%$ touching 93.89 mark. The last year of the pre-derivatives period records a decline by $23.63 \%$, touching 71.70 mark. The spread of volatility in terms of standard deviation throughout the pre-derivatives period stands at (30.12-132.14) levels, besides, the average level of volatility stands at 72.29 mark throughout the pre-derivatives period.

The post-derivatives period in the first year records the level of volatility at 40.43 mark in terms of standard deviation. This is followed by a substantial increase in the subsequent year by $156.54 \%$, touching 103.49 mark. This upward trajectory continues in the third year of the 
pre-derivatives period in which the level of volatility touches 110.19 mark, increasing by 6.47\%.The fourth year continues with this upward movement by registering a further rise in the level of volatility by $88.08 \%$ that pushes up the volatility level to 636.11 mark in terms of standard deviation which also stands as the highest level of volatility throughout the postderivatives period. However, the level of volatility witnesses a substantial decline in the subsequent year by $92.54 \%$, touching 15.46 mark which is followed by a further fall by $5.56 \%$, which pushes down the level of volatility to 14.60 mark in terms of standard deviation that also stands as the lowest level of volatility throughout the post derivatives period .The last year of the post-derivatives period registers an increase by $26.30 \%$ that takes the level of volatility to 18.44 mark. The spread of volatility in terms of standard deviation throughout the postderivatives period stands at (14.60-626.11) levels, besides, the average level of volatility in terms of standard deviation stands at 72.82 mark throughout the post-derivatives period.

\section{CONCLUSION}

This study has been undertaken so as to establish the impact of derivatives products on the volatility of the underlying stocks. After undergoing the analysis of the data, the study established that the introduction of stock futures trading influenced the levels of volatility of the underlying stocks in a significant manner. The analysis of the stocks that represent the pharmaceutical industry reveals that the level of volatility has witnessed an increase after the inception of stock futures contracts on these stocks. These findings are confirmed by a comparative study of the statistical scores of pre-derivatives period and post-derivatives period.

The representative stocks of the banking industry do register statistically significant impact on part of the introduction of derivatives products on the volatility of the underlying as these stocks have shown significant upward trajectory in the level of volatility throughout the postderivatives period. The automobile industry is represented by two stocks which have thrown a conclusive verdict in favour of the argument that the inception of stock futures increased the level of volatility as both the sample stocks that represent this industry has registered an increase in the level of volatility throughout the post-derivatives period.

Thus, the overall empirical findings reveal that the listing of stock futures have brought about, statistically, a significant increase in the level of volatility during the post-derivatives period compared to pre-derivatives period. These findings are strongly backed up by the comparative analysis of the statistical scores of the pre-derivatives and post-derivatives period. Hence, it can be concluded on the basis of the statistically significant findings that stock futures have had an adverse impact on the volatility of the underlying stocks. These findings also collaborate with the findings of Lee and Oak (1992), Bechetti and Robert (1999) and Kamara et.al (1992).

\section{References:}

Lee Sang Bin and Ohk Ki Yod (1992): "Relationship between Stock Index Futures Listing and Structural Changes in Time-Varying." Journal of Futures Market, 12 (05):493-509.

M, Thenmozhi (2002): Futures Trading, Information and Spot Price Volatility of NSE-50 Index Futures Contracts. www.nseindia.com

Bechetti, S. and Robert, D. J. (1999): “Will Increased Regulations of Stock Index Futures Reduced Stock Market Volatility?" Federal Reserve Bank of Kansas City Economics Review. (Nov/Dec), pp. 33-46.

Antonios Antonion and Phil Holmes (1995): "Futures Trading Information and Spot Price Volatility: Evidence for the FTSE-100 Stock Index Futures Contracts using GARCH Model.” Journal of Banking and Finance, 19:117-129.

Kamara, A; Miller Junior, T. W. and Segel, A. F. (1992): "Effects of Futures Trading on the Stability of Index S\&P 500 Returns." Journal of Futures Market, 12:645-658. 
Mekenzie Michael, D; Brailsford, T. J. and Robert, W. Faff (2001): “New Insights into the Impact of the Introduction of Futures Trading on Stock Price Volatility." Journal of Futures Market, 21(3):237-255.

Brorsen, B. Wade (1991): “Futures Trading Transaction Costs and Stock Market Volatility.” Journal of Futures Market, 11(2):153-163.

Golaka, C. Nath (2006): Behaviour of Stock Market Volatility after Derivatives. (www.nseindia.com).

Chatrath Arjun; Ram chander Sanjay and Sang Frank (1998): "The Role of Futures Trading Activity in Exchange Volatility." Journal of Futures Market, 05:561-584.

Ganai, K. A. (2019): “Correlates of Index Futures and Spot Index Volatility: A Study of Indian Stock Market." Archives of Business Research, 7(2) 245-252.

Sangmi, Khurshid and Khalid (2013): "Derivatives Trading in Emerging Economies with Special Reference to India" Journal of Accounting and Management, JAM Vol.3, no. 1 (2013).

Eric C. Chang, Joseph w. Cheng and Michael Pinegar (1999): "Does Futures Trading Increase Stock Market Volatility? The Case of the Nikkei Stock Index Futures Market." Journal of Banking and Finance. Volume 23, Issue 5, May 1999, Pages 727-753.

Darren Butterworth (2010): "The impact of futures trading on underlying stock index volatility: The case of the FTSE Mid 250 contract." Applied Economics Letters, Volume 7, Page 439-442, 2010.

Kamara, A; Miller Junior, T. W. and Segel, A. F. (1992): "Effects of Futures Trading on the Stability of Index S\&P 500 Returns." Journal of Futures Market, 12:645-658.

Mekenzie Michael, D; Brailsford, T. J. and Robert, W. Faff (2001): “New Insights into the Impact of the Introduction of Futures Trading on Stock Price Volatility." Journal of Futures Market, 21(3):237-255.

Golaka, C. Nath (2006): Behaviour of Stock Market Volatility after Derivatives. (www.nseindia.com). 